\title{
DIRETRIZES PARA PROJETO ARQUITETÔNICO DE MOBILIDADE URBANA E INTEGRAÇÃO SOCIAL EM PRESIDENTE VENCESLAU
}

João Victor de Souza Lima', Maria Alessandra Bacaro Boscoli²

${ }^{1}$ Discente do curso de Arquitetura e Urbanismo da Universidade do Oeste Paulista - UNOESTE. ${ }^{2}$ Docente do curso de Arquitetura e Urbanismo da Universidade do Oeste Paulista - UNOESTE. E-mail: jv_al182@hotmail.com

\section{RESUMO}

O trabalho em questão consiste na pesquisa preparatória para a criação de um complexo de entretenimento, cultura e apoio em Presidente Venceslau, cidade do interior de São Paulo. A pesquisa se justifica pela necessidade da cidade de possuir um estabelecimento que, voltado para esse fim, proporcione soluções para os problemas que a abrangem, relacionados a ócio urbano, vazios e barreiras urbanas e segregação social. O trabalho busca então artifícios para a elaboração de um projeto que resolva ou amenize os problemas evidenciados, através de estudos sobre 0 desenvolvimento histórico das problemáticas, análise do foco de ação, e estudos sobre estratégias projetuais. Como resultado, a pesquisa proporciona diretrizes subsidiais para as definições posteriores do projeto arquitetônico acadêmico que será elaborado.

Palavras-chave: Segregação Social; Barreira Urbana; Vazios Urbanos, Ócio Urbano.

\section{INTRODUÇÃO}

Presidente Venceslau é uma cidade pequena do extremo oeste do estado de São Paulo, com aproximadamente $\mathbf{3 8 . 0 0 0}$ habitantes, se inserindo na região denominada como "Alta Sorocabana".

Em análise empírica, percebe-se a segregação social sofrida pelas duas extremidades de Presidente Venceslau (norte e sul), uma segregação psicológica e física causada por um desenho urbano que se desenvolveu há décadas atrás acima da supervalorização de uma parcela da cidade em detrimento da desvalorização de outra, resultado do método de colonização do povoado. Essa segregação física tem seu ponto polarizador na linha férrea da cidade, pois, foi a partir daí que começou a se consolidar. O pátio dessa linha férrea, por sua vez, constitui uma grande parcela dos vazios urbanos da cidade, possuindo grandes potenciais para abrigar projetos voltados para recreação e integração social, mas estando estagnado, sem uso, transformando-se em uma barreira urbana física e psicológica em certos períodos do dia.

A pesquisa em questão objetiva encontrar diretrizes para a criação do projeto urbano-arquitetônico de um complexo de entretenimento integrador implantado em uma parcela desse pátio, que diminua os efeitos da estagnação urbana sofrida por Presidente Venceslau, buscando benefícios de diversidade, mobilidade urbana e integração social através de espaços que 
ofereçam serviços, percursos, e pontos de encontro para a população. As diretrizes buscarão proporcionar um projeto que consiga migrar os pontos de encontro da cidade para um ambiente mais propício a isso, de modo que sua diversidade de usos seja irradiada ao entorno do complexo, e sua composição reestabeleça a proximidade social, tanto entre as classes sociais, quanto dessas classes com o espaço público e a cidade como um todo, utilizando-se dos recursos privados e semiprivados para gerar atrativos para a população em geral, sem intimidar os usuários que não pretendem consumir.

\section{HISTÓRICO}

A colonização de Presidente Venceslau iniciou-se na década de 20, através da extração de madeira. Segundo Dita (2006), a linha férrea chegou na Alta Sorocabana com o intuito de exploração do local, e como a madeira do mesmo era proveniente para vários usos, iniciou-se a extração. Com isso, a vegetação nativa acabou por ser devastada e, como resultado, se abriram grandes extensões de solo nu. As glebas resultantes foram então apossadas pelos desbravadores e vendidas para agricultores imigrantes que chegavam nessa região em busca de seu pedaço de terra. Deu-se início então, na década de 30, ao período da agricultura em Presidente Venceslau, que, desde o início, se baseou na monocultura. Segundo Dita (2006), a primeira cultura exercida no povoado foi a do café, realizada em massa pela maior parte dos proprietários de terra, imigrantes de outros países que no povoado se instalavam.

A segregação social existente em Presidente Venceslau teve sua origem a partir de fatores condicionados pela própria monocultura exercida na cidade. Segundo Erbella (2009), inicialmente, as áreas colonizadas pelos imigrantes de outros países (que realizam a monocultura do café) se localizavam em sua maioria ao norte da linha férrea, enquanto a área ao sul da mesma só foi colonizada no período da monocultura do algodão. Esse fator influenciou drasticamente para a dualidade econômica e social entre a parcela norte e a parcela sul da cidade, uma vez que, segundo Erbella (2009), enquanto a primeira fora povoada pelos próprios proprietários de terra, a segunda foi povoada por imigrantes nordestinos que serviam como mão de obra terceirizada, trabalhando para esses proprietários na monocultura do algodão de forma quase escravizada. Esses trabalhadores que viviam em condições desumanas não possuíam as terras nas quais produziam, mas habitavam essas áreas, constituindo assim a maior parcela demográfica do povoado que se consolidou na região sul da cidade. Como resultado, houve, desde o início, uma colonização desequilibrada socialmente e economicamente, onde, ao norte da linha férrea, o 
povoado constituía uma classe econômica mais elevada (basicamente colonizadores imigrantes de outros países), e, ao sul da linha férrea, o povoado constituía uma classe econômica desfavorecida em sua maioria (basicamente trabalhadores nordestinos).

\section{PROBLEMÁTICAS}

Presidente Venceslau teve então sua segregação social determinada já no início da sua colonização. Uma segregação que, inicialmente, era baseada por questões psicológicas e evolutivas, hoje é determinada pelas distâncias físicas. Por mais que a discriminação acima da diferença social e econômica não mais exista na cidade, ainda existe a segregação psicológica de senso comum, na qual quem mora a norte da linha férrea é considerado, automaticamente, "mais rico" do que quem mora a sul desse limite. Essa segregação psicológica encontra sua explicação quando Jacobs (2007, p. 285) afirma que "as linhas férreas são um exemplo clássico de fronteira, tanto que passaram a significar, há muito tempo, também fronteiras sociais - 'do outro lado da linha do trem'.". Paralelamente, existe a clara valorização imobiliária das áreas a norte da linha férrea em detrimento à desvalorização das áreas a sul, de modo que, comparando os bairros localizados nas extremidades de cada uma dessas faces, percebe-se claramente a diferença social e econômica dos mesmos, o que retrata que hoje as classes sociais estão segregadas pelas distâncias físicas entre elas, não existindo espaços e recursos estimuladores de integração entre as mesmas.

Em outro ponto de análise, o pátio da FEPASA (Ferrovia Paulista AS), limite da segregação social no município, também configurar outro grande problema. Em vários trechos, esse pátio se abre em grandes vazios, os quais se tornam fronteiras insalubres, vandalizadas e perigosas em períodos noturnos, mesmo sendo utilizado como atalho em alguns períodos do dia. Isso acontece pelo fato de ele ser um enorme vazio urbano longitudinal que assume basicamente uma única função principal: a linha férrea.

Segundo Jacobs (2007, p. 287), “O problema básico das fronteiras, como vizinhas da cidade, é que elas costumam formar becos sem saída para a maioria das pessoas que utilizam as ruas". Isso intensifica o processo de abandono dessas áreas, além de dificultar os acessos entre as parcelas norte e sul da cidade - por mais que existam vias transcendentes que facilitem o trânsito de automóveis, não condicionam os pedestres a usarem o atalho no período noturno, de modo que eles ainda evitam o trajeto devido a sua ociosidade. 


\section{DESENVOLVIMENTO: DIRETRIZES INICIAIS}

Segundo del Rio (1990), a morfologia de um espaço urbano é constituída pelo seu traçado bidimensional adquirido pela evolução da cidade, consolidado e modificado pelo tempo, através das ações humanas, e, por esse motivo, dificilmente consegue ser alterada, a não ser através de uma reforma urbana completa. Já as características visuais se constituem pela imagem tridimensional do espaço, algo facilmente mutável, e que, dessa forma, se modifica periodicamente. As condições morfológicas e visuais de um espaço, somadas com as bagagens culturais, sociais e econômicas de cada usuário do mesmo, geram uma percepção desse espaço por esses usuários, que, por sua vez, gera um comportamento nesses usuários. Entendendo o que faz os usuários perceberem um espaço de tal forma, consegue-se entender o porquê de os mesmos assumirem determinado comportamento sobre esse espaço. Dessa forma, é possível gerar mudanças visuais sutis, pontuais ou totalizadoras que gerem uma mudança de percepção desse espaço e, consequentemente, do comportamento dos usuários, sem que a morfologia precise ser alterada.

A morfologia de Presidente Venceslau se consolidou, com o tempo, de modo que houve uma segregação física estabelecida através de um limite central, o pátio da FEPASA. Essa fronteira faz com que a percepção da população em geral (principalmente da classe de alto poder aquisitivo) seja de que a parcela a norte da linha férrea é o espaço dos mais ricos, e a parcela a sul da mesma é o espaço dos mais pobres, impedindo que as duas faces da cidade consigam ser unificadas ao olhar da população. Através da evolução morfológica e da formação visual (tridimensional) que se estabeleceu ao seu redor, esse pátio se tornou também um vazio urbano e uma barreira psicológica, por se constituir de uma grande extensão longitudinal atribuída a uma única função que hoje não possui funcionamento, e pelo fato de a maior parte das atividades exercidas em suas adjacências se voltarem contra ele, fazendo com que a percepção dos usuários seja de um espaço negligenciado e perigoso, e, desta forma, que não seja utilizado espontaneamente por eles, mas sim evitado e usado eventualmente apenas como espaço de transição. Com isso, os usuários perdem a percepção de proximidade entre os espaços adjacentes à linha férrea, as distâncias se intensificam, os atalhos são trocados por grandes percursos (principalmente no período noturno), e o pátio da linha férrea acaba se tornando cada vez mais abandonado.

O projeto do complexo de entretimento não modificará a morfologia da cidade, mas conseguirá modificar as condições visuais e funcionais do pátio da FEPASA, e, consequentemente, 
a percepção e o comportamento da população em relação ao mesmo, tanto no intuito de amenizar a segregação sócio-espacial, quanto de erradicar o vazio e a barreira urbana que esse pátio produz. Com esses objetivos, a pesquisa encontrou as diretrizes iniciais descritas a seguir.

\subsection{Diversidade de Usos e de Fluxos}

O fato de o pátio da linha férrea se tornar um "beco sem saída" para a população evidencia a importância de um projeto que facilite o acesso entre as duas extremidades desse limite, e que crie um percurso dentro dele, transformando essa barreira em um atalho. Além disso, as atividades proporcionadas pelo complexo precisarão erradicar os problemas de ócio urbano dessa barreira, produzindo diversidade de usos e opções de fluxo suficientes para dissolver esses problemas.

No âmbito da diversidade de usos, Jacobs (2007) afirma que a melhor maneira de evitar o ócio urbano e o surgimento de barreiras é a geração de uma grande variedade de usos principais, ou seja, a criação de atividades de diferentes focos. Isso faz com que os espaços onde essas diversidades são geradas se encontrem em uso constante em todos os períodos do dia, pois, em cada período, um tipo de uso atrairá um público diferente para ele. Para Jacobs (2007, p.298), “o máximo possível de elementos urbanos deve ser usado para construir um território misto, vivo, e o mínimo possível deve ser usado para a criação desnecessária de barreiras". Uma vez que a principal causa de o pátio da FEPASA ser uma barreira na cidade ser a sua grande dimensão longitudinal atribuída a um único uso principal, ressalta-se a importância de que o complexo possua maleabilidade para abrigar usos variados em horários variados, para evitar que a barreira que antes existia a noite, agora exista a luz do dia. Dessa forma, tornou-se necessária a fragmentação do percurso delimitado, de acordo com a tipologia de seu entorno, para que fossem analisadas as particularidades de ambiências do mesmo, e assim, encontrados os programas de necessidades para cada uma delas. Como resultado, o complexo atenderá não só os usos de entretenimento, mas também os culturais, de lazer, educação e apoio social.

No âmbito dos fluxos, é importante que o projeto proporcione várias opções de entradas, saídas, e atalhos, de modo que não intensifique o efeito de "beco sem saída" que as barreiras urbanas produzem, em particular, o pátio da linha férrea. Dessa forma, o complexo deverá possuir vários espaços de transição entre os pavilhões para que seja possível o acesso de qualquer ponto dele para o espaço público e vice-versa. Assim, o usuário poderá utilizar o espaço inteiramente como percurso único, mas também terá a liberdade de usá-lo como atalho, sem que 
o complexo barre os acessos e vias automóveis já existentes, transcendendo por cima delas quando existirem intersecções.

\subsection{Espaços Positivos e Negativos}

Segundo Frederick (2010), espaços positivos são aqueles nos quais as pessoas se fixam, pois eles dão aos usuários o sentido de local de permanência, sendo construídos ou não construídos, enquanto os espaços negativos são aqueles nos quais as pessoas apenas transitam, pois dão aos usuários o sentido único de espaço de locomoção ou transição. Para Frederick (2010), a perda do sentido de espaço de permanência e a restrição para espaço de transição acontecem, muitas vezes, porque as construções adjacentes não abraçam esses espaços para que se tornem locais de convivência, uma vez que focam seus esforços apenas em suas formas, deixando a forma do espaço externo como mera sobra acidental. Ressalta-se então, no projeto que será elaborado, a criação de espaços negativos que também assumam o papel de espaços positivos, através da unicidade dos pavilhões com esses espaços de transição. Isso pode gerar uma grande mobilidade ao projeto, uma vez que a população utilizará os intervalos entre os pavilhões do complexo como atalho de transição e, ao mesmo tempo, como local de permanência e convivência, sem que as duas funções sejam separadas. A partir desse pressuposto, o projeto buscará o máximo de aproveitamento dos intervalos entre os pavilhões, de modo que os blocos não sejam interrompidos, mas se estendam para os "espaços abertos", emprestando a eles a sua condição de permanência, tornando-os assim espaços positivos, por mais que também sejam usados como atalhos e espaços de transição.

\section{3 Âncoras Projetuais}

Segundo Frederick (2010, p. 87), “As âncoras são os elementos de projetos que, inerentemente, atraem pessoas a eles." Essas âncoras conseguem conduzir o usuário dentro do percurso, funcionando como metas: O usuário passa por espaços os quais não os atrairiam inicialmente, no intuito de transitar entre os espaços âncoras, que são os seus principais atrativos. Consequentemente, acabam se sentindo a vontade para utilizar os espaços intermediários, antes não tão atraentes. Dessa forma, "A localização cuidadosa de âncoras pode gerar um interior ativo em seu edifício." (FREDERICK, 2012, p. 87). No projeto do complexo, as âncoras abrigarão as atividades de entretenimento e apoio mais atrativas para a população de modo que sejam metas 
de interesse para o usuário. O percurso intermediário consistirá naquelas atividades que, a primeira vista, não são tão atraentes para esses usuários, as atividades culturais.

Outro ponto importante no uso das âncoras é a valorização de espaços prejudicados pela segregação social. Marques (2004) explica em sua obra que as "políticas públicas" são estratégias do estado para diminuir os efeitos da segregação social e espacial, tentando equilibrar ao máximo as condições dos dois lados segregados, para que as diferenças sejam minimizadas cada vez mais, e a homogeneidade de acessos e oportunidades seja cada vez maior. Dentre as políticas públicas de combate à segregação, Marques (2004, p.51) aponta as que: "misturam grupos (agem sobre a segregação)", que consistem na "produção forçada de percursos", inserindo atividades atraentes para a população mais rica (culturais, educativas ou de entretenimento) em bairros pobres; e as que "reduzem desigualdade (agem sobre a desigualdade de acesso)", que consistem na "distribuição de equipamentos e serviços em áreas periféricas" em busca de proporcionar uma maior facilidade de acesso desses serviços para a população mais pobre, elevando sua situação para um padrão mais próximo do experimentado pelos grupos de melhor condição social.

O complexo em si naturalmente promoverá a mistura social direta, pois proporcionará espaços que atraiam tanto os mais ricos quanto os mais pobres, sem que ninguém se sinta intimidado. As âncoras, por sua vez, promoverão o intercâmbio entre os moradores de áreas mais nobres para as áreas mais carentes através da "produção forçada de percursos": a primeira âncora se localizará na região central da cidade, na proximidade de bairros de alto poder aquisitivo, enquanto a segunda âncora se localizará em outro ponto do percurso do pátio da FEPASA, já a sul da fronteira, em um bairro carente, de modo que os usuários mais ricos serão conduzidos a sair de sua zona de conforto e conhecer esse bairro. Paralelamente, a localização da segunda âncora no bairro carente proporcionará facilidade de acesso aos serviços de apoio, cultura e entretenimento para essa população, assim valorizando o bairro como um todo.

\section{CONSIDERAÇÕES FINAIS}

Identificando os problemas de Presidente Venceslau referentes ao ócio urbano, aos vazios e barreiras urbanas e à segregação social, a pesquisa buscou artifícios e diretrizes iniciais para formular um conceito de complexo de entretenimento, cultura e apoio que consiga atender às necessidades da população, ao mesmo tempo em que crie um percurso movimentado e em atividade constante em todos os seus trechos, através do uso de âncoras projetuais, da articulação entre espaços positivos (de permanência) e negativos (de transição) e da diversidade de usos 
principais e de fluxos. Isso fará com que um dos grandes espaços ociosos da cidade, o pátio da linha férrea, que constitui sua principal barreira urbana, se torne um trajeto atraente e diversificado para os pedestres, e assim, perca sua imagem de barreira para assumir a imagem de atalho e ícone de convivência. O complexo também fragilizará a segregação social, através da mistura de atrativos referentes a todas as classes, e da condução de determinada classe para a realidade de sua classe oposta, através das âncoras. Sua inserção exatamente no limite segregador da cidade erradicará a barreira psicológica segregativa hoje existente.

Em resumo, as táticas estipuladas vêm na intenção de transformar a percepção e comportamento da população através do complexo e seus elementos, sem que seja necessária a reforma morfológica do espaço.

\section{REFERÊNCIAS}

DEL RIO, Vicente. Introdução ao Desenho Urbano no Processo de Planejamento. 1. ed. São Paulo: Editora Pini, 1990.

DITA, Nilda da Silva. Presidente Venceslau: Vocação Solidária - 80 Anos, Suas Histórias, Suas Conquistas!. 1. ed. São Paulo: Editora Noovha America, 2006.

ERBELLA, Inocêncio. Rabiscos Históricos de Presidente Venceslau. 1. ed. Presidente Venceslau: Editora Artes Gráficas Pedriali LTDA, 2006.

FREDERICK, Matthew. 101 Lições Que Aprendi na Escola de Arquitetura. 1. ed. São Paulo: Martins Editora, 2010.

JACOBS, Jane. Morte e Vida de Grandes Cidades. 1. ed. São Paulo: Editora Martin Fontes, 2007.

MARQUES, Eduardo Cesar. Segregação, Pobreza e Desigualdades Sociais. 1.ed. São Paulo: Editora Senac, 2004. 